\section{Original Article}

\section{Corresponding Author}

Kern Singh

(iD https://orcid.org/0000-0002-6118-7273

Department of Orthopaedic Surgery, Rush

University Medical Center, 1611 W.

Harrison St, Suite \#300, Chicago, IL 60612,

USA

Tel: +1-312-432-2373

Fax: +1-708-409-5179

E-mail: kern.singh@rushortho.com

Received: February 17, 2018

Revised: April 24, 2018

Accepted: April 29, 2018

\title{
Postoperative Fever Evaluation Following Lumbar Fusion Procedures
}

\author{
Benjamin C. Mayo, Brittany E. Haws, Daniel D. Bohl, Philip K. Louie, Fady Y. Hijji, \\ Ankur S. Narain, Dustin H. Massel, Benjamin Khechen, Kern Singh \\ Department of Orthopaedic Surgery, Rush University Medical Center, Chicago, IL, USA
}

Objective: This study aimed to determine the incidence of postoperative fever, the workup conducted for postoperative fever, the rate of subsequent fever-related diagnoses or complications, and the risk factors associated with fever following lumbar fusion.

Methods: A retrospective review of patients undergoing lumbar fusion was performed. For patients in whom fever $\left(\geq 38.6^{\circ} \mathrm{C}\right)$ was documented, charts were reviewed for any fever workup or diagnosis. Multivariate regression was used to identify independent risk factors for the development of postoperative fever.

Results: A total of 868 patients met the inclusion criteria, of whom 105 exhibited at least 1 episode of fever during hospitalization. The first documentation of fever occurred during the first 24 hours in $43.8 \%$ of cases, during postoperative hours $24-48$ in $53.3 \%$, and later than 48 hours postoperatively in $2.9 \%$. At least 1 component of a fever workup was conducted in 47 of the 105 patients who had fever, resulting in fever-associated diagnoses in 4 patients prior to discharge. Three patients who had fever during the inpatient stay developed complications after discharge. On multivariate analysis, operations longer than 150 minutes (relative risk $[R R], 1.66 ; \mathrm{p}=0.015$ ) and narcotic consumption greater than 85 oral morphine equivalents on postoperative day $0(R R, 1.53 ; \mathrm{p}=0.038)$ were independently associated with an increased risk of developing postoperative fever.

Conclusion: The results of this study suggest that inpatient fever occurred in roughly 1 in 8 patients following lumbar fusion surgery. In most cases where a fever workup was performed, no cause of fever was detected. Longer operative time and increased early postoperative narcotic use may increase the risk of developing postoperative fever.

Keywords: Lumbar fusion, Postoperative fever, Infection, Complication, Urinary tract infection, Pulmonary embolism

\section{INTRODUCTION}

Postoperative fever is a common occurrence following both general and orthopedic surgical procedures, with a reported incidence between $10 \%$ and $73 \% .^{1-5}$ Postoperative complications such as urinary tract infection (UTI), sepsis, pneumonia (PNA), surgical site infection (SSI), deep vein thrombosis (DVT), and pulmonary embolism (PE) may result in pyrexia. ${ }^{6-9}$ However, not all postoperative fevers are a cause for concern nor do they all necessitate immediate evaluation, as intraoperative tissue damage and inflammation may also result in pyrexia. ${ }^{9-11}$
When postoperative fevers do arise, further workup including urinalyses (UA), urine cultures, blood cultures, chest radiographs (chest X-ray, CXR), or sputum cultures are often ordered to determine the etiology of the postoperative fever and to rule out potentially dangerous complications. ${ }^{12}$ However, fever workups can be expensive, time consuming, prolong hospitalization, and are often inconclusive. ${ }^{5,13-15}$ As such, it is essential for physicians to understand the utility of these tests and at what point they should be ordered.

The necessity of fever evaluation has previously been examined following both general ${ }^{16-18}$ and orthopaedic surgeries. ${ }^{12}$ Howev- 
er, a large majority of the orthopedic literature has focused on fevers following total joint arthroplasty, $2,4,6,8,9,11,12,14,19-21$ while fever management following orthopedic spine procedures ${ }^{22-24}$ has not been well assessed. In this context, the purpose of this study is to describe the frequency and timing of postoperative fevers, the results of fever workups, and the risk factors for developing postoperative fevers following lumbar fusion procedures.

\section{MATERIALS AND METHODS}

Following Institutional Review Board approval (ORA\# 14051 301 ), a prospectively maintained database of consecutive patients undergoing elective lumbar fusion procedures by a single surgeon from 2005-2016 was reviewed. Patients undergoing any level, primary or revision transforaminal (TLIF), posterior (PLIF), anterior (ALIF), or lateral (LLIF) lumbar interbody fusions were eligible for inclusion in the study. Patients undergoing fusion for degenerative or isthmic spondylolisthesis, spinal stenosis, degenerative disc disease, or herniated nucleus pulposus were included. Patients undergoing fusion for infection, fracture, or those in which a concurrent corpectomy was performed were excluded from the analysis. Concurrent corpectomy patients were excluded in order to standardize the patient population to only include those undergoing interbody fusion.

As part of routine protocol, temperature was taken every 4 hours on postoperative inpatients. The first temperature is recorded as soon as the patient arrives into the postanesthesia care unit. For patients in whom any postoperative fever (temperature $\geq 38.6^{\circ} \mathrm{C}$ ) was documented, both inpatient charts and postoperative outpatient clinic notes were further reviewed for any fever workup, diagnoses that may have potentially resulted in elevated body temperature, and treatment given. Components of a fever workup included UA, urine culture, CXR, blood culture, sputum culture, venous duplex ultrasound, and chest computed tomography (CT). Components of the workup performed were not standardized and depended on the clinical suspicion. Diagnoses that were considered to be complications causing fever included SSI, UTI, PNA, DVT, and PE. Other causes of fever such as atelectasis were also recorded if diagnosed after CXR. However, these were not characterized as complications as they are causes of fever that do not require changes in standard postoperative management. At our institution, barring any associated symptoms, a temperature $\geq 38.6^{\circ} \mathrm{C}$ within 48 hours after surgery prompts intervention in the form of acetaminophen (if tolerable by the patient), an ice pack wrapped in a towel, and instructions to use the incentive spirometer 10 times per hour.
These may be applied individually or in combination.

Results of fever workups were summarized using descriptive statistics, and multivariate Poisson regression with robust error variance was used identify independent risk factors for the development of fever. Potential risk factors investigated included: age of 60 years old or greater, male sex, smoking, a Charlson Comorbidity Index ${ }^{25}$ score greater than 1, presence of diabetes mellitus, posterior operative approach, revision fusion procedure, undergoing an operation on greater than 1 level, a body mass index greater than or equal to $30 \mathrm{~kg} / \mathrm{m}^{2}$, an operative time greater than or equal to 150 minutes, an estimated blood loss

Table 1. Patient characteristics $(n=868)$

\begin{tabular}{|c|c|}
\hline Characteristic & Value \\
\hline Age (yr) & $52.1 \pm 13.0$ \\
\hline \multicolumn{2}{|l|}{ Sex } \\
\hline Female & $361(41.59)$ \\
\hline Male & $507(58.41)$ \\
\hline \multicolumn{2}{|l|}{ Obesity } \\
\hline Nonobese $\left(<30 \mathrm{~kg} / \mathrm{m}^{2}\right)$ & $457(52.65)$ \\
\hline Obese $\left(\geq 30 \mathrm{~kg} / \mathrm{m}^{2}\right)$ & $411(47.35)$ \\
\hline \multicolumn{2}{|l|}{ Smoking status } \\
\hline Nonsmoker & $573(77.22)$ \\
\hline Smoker & $169(22.78)$ \\
\hline Ageless comorbidity burden (CCI) & $1.26 \pm 1.38$ \\
\hline \multicolumn{2}{|l|}{ Diabetes mellitus } \\
\hline Not diabetic & $784(90.32)$ \\
\hline Diabetic & $84(9.68)$ \\
\hline \multicolumn{2}{|l|}{ Procedure type } \\
\hline Primary & $656(83.25)$ \\
\hline Revision & $132(16.75)$ \\
\hline \multicolumn{2}{|l|}{ Operative approach } \\
\hline Anterior/lateral & $191(22.06)$ \\
\hline Posterior & $675(77.94)$ \\
\hline \multicolumn{2}{|l|}{ Number of levels } \\
\hline 1 Level & $760(88.27)$ \\
\hline 2 Level & $91(10.57)$ \\
\hline 3 Level & $10(1.16)$ \\
\hline Operative time (min) & $142.66 \pm 71.13$ \\
\hline Estimated blood loss (mL) & $77.29 \pm 98.35$ \\
\hline Length of stay (hr) & $60.92 \pm 39.63$ \\
\hline POD 0 narcotic (OME) & $88.53 \pm 69.83$ \\
\hline
\end{tabular}

Values are presented as mean \pm standard deviation or number (\%). CCI, Charlson Comorbidity Index; POD, postoperative day; OME, oral morphine equivalent. 
greater than or equal to $100 \mathrm{~mL}$, and narcotic consumption on postoperative day (POD) 0 greater than or equal to 85 oral morphine equivalents (OMEs). Statistical significance was set at $\mathrm{p}<0.05$.

\section{RESULTS}

A total of 868 patients undergoing lumbar fusion procedures met inclusion criteria and were included in the analysis (Table 1). A majority of patients underwent procedures that were 1-level procedures (88.3\%). Similarly, a majority were posterior-only fusion procedures (77.9\%).

A total of 105 patients (12.1\%) exhibited at least one episode of fever during their hospital course. Of those who developed fevers, 64 (61.0\%) had only one documented fever, 15 (14.3\%) had two documented fevers, and 26 (24.7\%) had 3 or more documented fevers (Fig. 1). A $43.8 \%$ of first-documented fevers occurred during the first 24 hours following surgery, 53.3\% during postoperative hours $24-48$, and $2.9 \%$ following 48 hours (Fig. 2).

Table 2 describes risk factors associated with the development of a postoperative fever. Male sex (relative risk [RR], 1.53; $\mathrm{p}=$ $0.039)$, revision fusion procedures $(R R, 1.63 ; p=0.031)$, and operative duration greater than 150 minutes $(R R, 1.69 ; \mathrm{p}=0.006)$ were identified as risk factors for the development of a postoperative fever. On multivariate analysis, operations longer than 150 minutes $(\mathrm{RR}, 1.70 ; \mathrm{p}=0.009)$ and narcotic consumption greater than 85 OMEs on POD 0 (RR. 1.56; $\mathrm{p}=0.027$ ) were in-

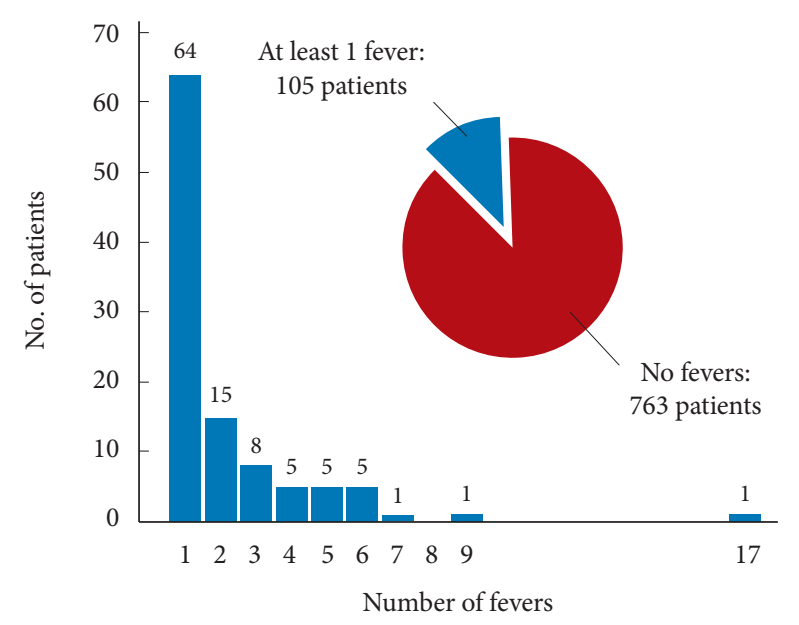

Fig. 1. Number of fevers following lumbar fusion. Of those who developed fevers, $64(61.0 \%)$ had only one documented fever, 15 (14.3\%) had 2 documented fevers, and $26(24.7 \%)$ had 3 or more documented fevers. dependently associated with increased risk of developing postoperative fever (Table 3 ).

At least one component of a fever workup was conducted in 47 of the 105 patients (44.8\%) who had a fever (Fig. 3). Urinalysis was performed in 43 patients $(41.0 \%)$, urine culture in 33 patients (31.4\%), CXR in 25 patients (23.8\%), blood cultures in 8 patients (7.6\%), duplex ultrasound in 2 patients (1.9\%), CT

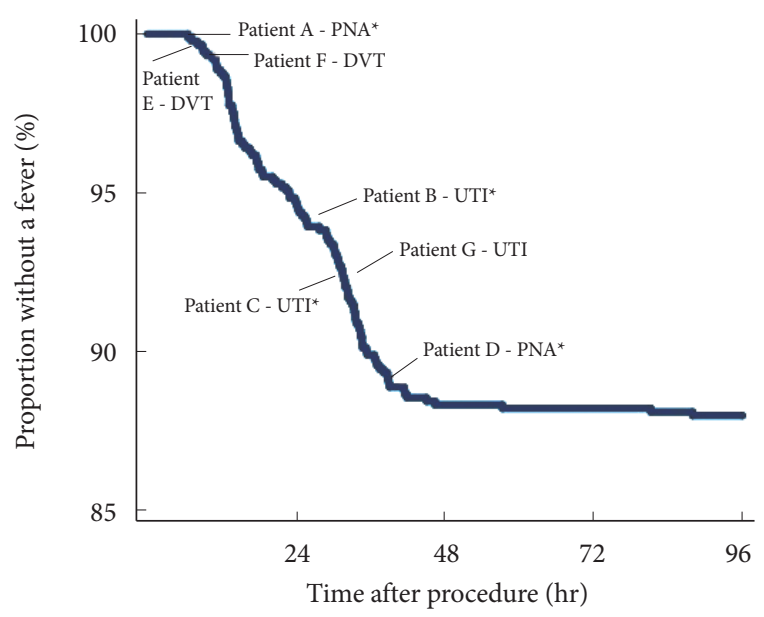

Fig. 2. Timing of postoperative fever. A $43.8 \%$ of first-documented fevers occurred during the first 24 hours following surgery, $53.3 \%$ during postoperative hours $24-48$, and $2.9 \%$ following 48 hours. All patients diagnosed with a postoperative complication had their first documented fever during the first 48 postoperative hours. PNA, pneumonia; DVT, deep vein thrombosis; UTI, urinary tract infection. ${ }^{*}$ Complication was diagnosed during the inpatient stay.

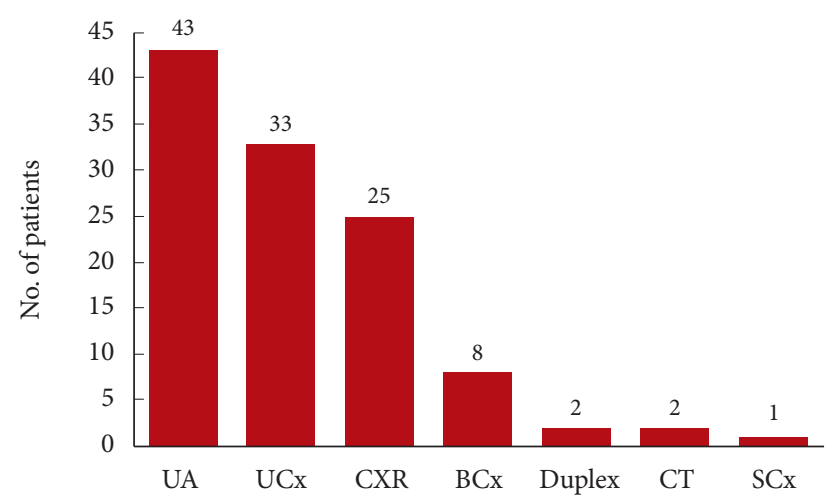

Fig. 3. Postoperative fever workups performed. At least one component of a fever workup was conducted in 47 of the 105 patients $(44.8 \%)$ who had a fever. Urinalysis (UA) was performed in 43 patients (41.0\%), urine culture (UCx) in 33 patients $(31.4 \%)$, chest $\mathrm{x}$-ray (CXR) in 25 patients $(23.8 \%)$, blood cultures $(\mathrm{BCx})$ in 8 patients $(7.6 \%)$, duplex ultrasound in 2 patients $(1.9 \%)$, CT chest in 2 patients $(1.9 \%)$, and sputum culture (SCx) in 1 patient (1.0\%). 
Table 2. Risk factors for postoperative fever

\begin{tabular}{|c|c|c|c|c|}
\hline Variable & No. $(\%)$ & $\mathrm{RR}$ & $95 \% \mathrm{CI}$ & p-value ${ }^{\dagger}$ \\
\hline Overall & 98/861 (11.38) & & & \\
\hline Age (yr) & & & & 0.953 \\
\hline $18-59$ & 69/604 (11.42) & Reference & - & \\
\hline$\geq 60$ & $29 / 228(12.72)$ & 0.99 & $0.66-0.49$ & \\
\hline Sex & & & & $0.039^{*}$ \\
\hline Female & $31 / 357(8.68)$ & Reference & - & \\
\hline Male & $67 / 504(13.29)$ & 1.53 & $1.02-2.29$ & \\
\hline Obesity & & & & 0.215 \\
\hline Nonobese $\left(<30 \mathrm{~kg} / \mathrm{m}^{2}\right)$ & $46 / 455(10.11)$ & Reference & - & \\
\hline Obese $\left(\geq 30 \mathrm{~kg} / \mathrm{m}^{2}\right)$ & $52 / 406(12.81)$ & 1.27 & $0.87-1.84$ & \\
\hline Current smoker & & & & 0.112 \\
\hline No & $70 / 571(12.26)$ & Reference & - & \\
\hline Yes & $13 / 168(7.74)$ & 0.63 & $0.36-1.11$ & \\
\hline Ageless CCI & & & & 0.827 \\
\hline$<2$ & $70 / 623(11.24)$ & Reference & - & \\
\hline$\geq 2$ & $28 / 238(11.76)$ & 1.05 & $0.69-1.58$ & \\
\hline Diabetes mellitus & & & & 0.092 \\
\hline Not diabetic & $84 / 778(10.8)$ & Reference & - & \\
\hline Diabetic & $14 / 83(16.87)$ & 1.56 & $0.93-2.62$ & \\
\hline Procedure type & & & & $0.031^{\star}$ \\
\hline Primary & $67 / 656(10.21)$ & Reference & & \\
\hline Revision & $22 / 132(16.67)$ & 1.63 & $1.05-2.54$ & \\
\hline Operative approach & & & & 0.547 \\
\hline Anterior/lateral & $24 / 190(12.63)$ & Reference & - & \\
\hline Posterior & $74 / 669(11.06)$ & 0.88 & $0.57-1.35$ & \\
\hline Number of operative levels & & & & 0.224 \\
\hline Single level & $82 / 753(10.89)$ & Reference & - & \\
\hline Multilevel & $16 / 108(14.81)$ & 1.36 & $0.83-2.24$ & \\
\hline Operative duration (min) & & & & $0.006^{*}$ \\
\hline$<150$ & $57 / 604(9.44)$ & Reference & - & \\
\hline$\geq 150$ & $41 / 257(15.95)$ & 1.69 & $1.16-2.46$ & \\
\hline Estimated blood loss (mL) & & & & 0.652 \\
\hline$<100$ & $80 / 688(11.63)$ & Reference & - & \\
\hline$\geq 100$ & $18 / 173(10.4)$ & 0.89 & $0.55-1.45$ & \\
\hline Narcotics usage $(\mathrm{OME})^{\ddagger}$ & & & & 0.066 \\
\hline$<85$ & $48 / 497(9.66)$ & Reference & - & \\
\hline$\geq 85$ & $49 / 357(13.73)$ & 1.42 & $0.98-2.07$ & \\
\hline
\end{tabular}

No. (\%), number with fever/total in group (rate of fever).

RR, relative risk; CI, confidence interval; CCI, Charlson Comorbidity Index; OME, oral morphine equivalent; POD, postoperative day. ${ }^{*} \mathrm{p}<0.05$, statistically significance. ${ }^{\dagger} \mathrm{p}$-value determined using Poisson regression with robust error variance. ${ }^{\star}$ Average OME consumed on POD 0.

chest in 2 patients (1.9\%), and sputum culture in 1 patient (1.0\%). Of the 47 patients who received a fever workup, the first work- up test was performed on POD 0 for 1 patient (2.1\%), POD 1 for 16 patients (34.0\%), POD 2 for 20 patients (42.6\%), POD 3 
Table 3. Independent risk factors for postoperative fever

\begin{tabular}{lccc}
\hline Variable & RR & $95 \%$ CI & p-value $^{\dagger}$ \\
\hline $\begin{array}{l}\text { Narcotics usage } \\
\text { < }(\mathrm{OME})\end{array}$ & & & 0.027 \\
$\quad 85$ OME & Reference & - & \\
$\geq 85$ OME & 1.56 & $1.05-2.32$ & \\
Operative duration $(\mathrm{min})$ & & & 0.009 \\
$\quad<150$ & Reference & - & \\
$\geq 150$ & 1.70 & $1.14-2.54$ &
\end{tabular}

$\mathrm{RR}$, relative risk; CI, confidence interval; OME, oral morphine equivalent; $\mathrm{POD}$, postoperative day.

${ }^{\star}$ Average OME consumed on POD $0 .{ }^{\dagger} \mathrm{p}$-value calculated using stepwise Poisson regression with robust error variance controlling for age, gender, obesity, smoking status, comorbidity burden, diabetes mellitus, operative approach, procedure type, number of levels fused, operative time, estimated blood loss, average narcotic use on postoperative day 0 .

in 6 patients (12.8\%), and POD 4 or later in 4 patients (8.5\%).

Detailed information on patients who developed postoperative complications is presented in Table 4. Of those with fevers, 4 patients (3.8\%) were diagnosed with an inpatient complication following workup (2 PNAs, 2 UTIs; Fig. 2). In these patients, 3 of 4 demonstrated other signs or symptoms that increased suspicion for a complication, including shortness of breath, tachycardia/oxygen desaturations, and dysuria. Additionally, 3 patients $(2.9 \%)$ who had fevers during the inpatient stay developed complications that were not recognized until after discharge (1 UTI, 1 DVT, and 1 patient with UTI and DVT). Notably, 2 of these 3 patients had each received at least one component of a fever workup as an inpatient that returned negative. The third patient developed a fever 13 hours after surgery that resolved within 10 hours. As such, the patient was presumed to have had a reactive fever, and no workup was performed. Subsequently, the patient developed postoperative urinary retention and consequentially had a length of hospitalization of 103 hours; DVT was diagnosed after discharge. No patient who developed complications had a history of their complication, nor had any medical comorbidities that may have put them at higher risk. Of the patients who received a fever workup without a diagnosed complication, 9 were diagnosed with atelectasis. No SSIs were detected in this series of patients.

\section{DISCUSSION}

The development of fevers following orthopedic surgery is a frequent event that may be indicative of complications such as infection or thrombosis. However, many instances of postoper- ative fever are simply postoperative inflammatory reactions or minor pathologies such as atelectasis and not associated with a complication. Although the utility of postoperative fever workup following general surgical, gynecologic, and total joint arthroplasty procedures has previously been reported, the occurrence of fever following orthopedic spine procedures has not been well studied. The present study aimed to investigate the frequency and timing of postoperative fevers and the results of subsequent fever workups following lumbar fusion procedures. This study also describes risk factors associated with postoperative fevers.

The results of the current study suggest that postoperative fever occurs in $12.1 \%$ of patients following lumbar fusion procedures. Most patients who exhibit a fever typically have only one instance of fever, which most commonly occurs in the first 48 hours following surgery. It has been reported that postoperative fevers that develop in the first 3 to 4 days following surgery are less likely to be indicative of infectious complications than are fevers that arise on POD 5 or later. ${ }^{26}$ Further, one study noted that patients who become febrile on PODs 1 and 2 are less likely to be experiencing an infectious complication than those with fevers occurring on PODs 3 to $5 .^{2}$ In the majority of patients who developed fever in the present study, no cause was determined. Many were presumed to have atelectasis or other self-limited pathology. Furthermore, the patients who were diagnosed with a complication before or shortly after discharge also had signs or symptoms consistent with an infectious cause. Those who experienced late complications developed symptoms several days after discharge that were likely unrelated to their inpatient fever. Additionally, patients who underwent longer operations and those who consumed a greater amount of narcotic medications on POD 0 were at greater risk of developing postoperative fever.

The incidence of postoperative fever in this study is lower than previous reporting in the spine literature. A previous investigation by Walid et al. ${ }^{24}$ reported fever rates following cervical or lumbar procedures of $41.7 \%$ and $25.8 \%$ using temperature cutoffs of $37.8^{\circ} \mathrm{C}$ and $38.3^{\circ} \mathrm{C}$, respectively. The higher fever rates compared to the present study are likely due to differences in temperature cutoffs as well as increased heterogeneity in the procedures performed. Seo et al..$^{23}$ also investigated postoperative fever following a variety of spinal procedures and reported a rate of $13.2 \%$ using a cutoff of $37.8^{\circ} \mathrm{C}$. However, only fevers that occurred on POD 3 or later and were without an identifiable cause were included, limiting the comparison to the present study. 
Table 4. Summary of patients who had positive diagnoses

\begin{tabular}{|c|c|c|}
\hline Patient information & Timeline of events & Summary of hospital course \\
\hline $\begin{array}{l}\text { Patient A } \\
29 \text { Female } \\
\text { PNA during stay } \\
\text { Discharge POD } 9 \\
\text { LOS } 219 \mathrm{hr} \\
\text { Revision MIS TLIF for } \\
\text { pseudomeningocele, } \\
\text { pseudarthrosis, } 1 \text { level }\end{array}$ & $\begin{array}{l}\text { Inpatient } \\
\text { POD } 0 \text { - Fever } 1\left(38.9^{\circ} \mathrm{C}\right), 11 \mathrm{hr} \\
\text { POD } 4 \text { - Fever } 2\left(39.2^{\circ} \mathrm{C}\right), 95 \mathrm{hr} \\
\text { POD } 4 \text { - WBC } \max (17.7) \\
\text { POD } 5 \text { - Fever } 6\left(40.0^{\circ} \mathrm{C}\right)^{\dagger}, 106 \mathrm{hr} \\
\text { POD } 5 \text { - UA/UCx - Normal } \\
\text { POD } 6 \text { - CXR - PNA } \\
\text { POD } 6 \text { - Duplex - Normal }\end{array}$ & $\begin{array}{l}\text { POD } 2 \text { - Underwent second surgery for persistent dural bleb } \\
\text { repair. } \\
\text { POD } 5 \text { - Developed sore throat, shortness of breath, cough. CXR } \\
\text { confirmed PNA. Given antibiotics for PNA and empirically for } \\
\text { meningitis due to history of CSF leakage. } \\
\text { POD } 7 \text { - Continued to have fevers from POD } 4 \text { until POD } 7 .\end{array}$ \\
\hline $\begin{array}{l}\text { Patient B } \\
75 \text { Female } \\
\text { UTI during stay } \\
\text { Discharge POD } 4 \\
\text { LOS } 97 \mathrm{hr} \\
\text { PLF, } 1 \text { level }\end{array}$ & $\begin{array}{l}\text { Inpatient } \\
\text { POD } 1 \text { - Fever } 1\left(38.8^{\circ} \mathrm{C}\right), 24 \mathrm{hr} \\
\text { POD } 3 \text { - Fever } 2\left(38.8^{\circ} \mathrm{C}\right)^{\dagger}, 79 \mathrm{hr} \\
\text { POD } 3 \text { - UA/UCX - UTI* } \\
\text { POD } 3 \text { - CXR - Atelectasis } \\
\text { POD } 3 \text { - BCX - Normal }\end{array}$ & $\begin{array}{l}\text { POD } 2 \text { - Foley catheter removed } \\
\text { POD } 3 \text { - No reported symptoms but due to fever acquired UA } \\
\text { and UCx which was positive for bacteria and leukesterase. } \\
\text { Started on antibiotics. } \\
\text { No WBC elevation during stay }\end{array}$ \\
\hline $\begin{array}{l}\text { Patient C } \\
73 \text { Female } \\
\text { UTI during stay } \\
\text { Discharge POD } 3 \\
\text { LOS } 78 \mathrm{hr} \\
\text { PLF, } 1 \text { level }\end{array}$ & $\begin{array}{l}\text { Inpatient } \\
\text { POD } 1 \text { - Fever } 1\left(39.1^{\circ} \mathrm{C}\right)^{\dagger}, 34 \mathrm{hr} \\
\text { POD } 1 \text { - Fever } 2\left(38.7^{\circ} \mathrm{C}\right), 35 \mathrm{hr} \\
\text { POD } 1 \& 2 \text { - UA/UCx - Normal } \\
\text { POD } 2 \text { - WBC } \max (12.0) \\
\text { POD } 3 \text { - UA - UTI* }\end{array}$ & $\begin{array}{l}\text { POD } 1 \text { - Had urinary urgency and frequency, no burning or } \\
\text { itching. } \\
\text { POD } 3 \text { - Symptoms resolved without treatment but UA demon- } \\
\text { strated blood, WBC, and leukesterase. Started on antibiotics. }\end{array}$ \\
\hline $\begin{array}{l}\text { Patient D } \\
29 \text { Male } \\
\text { PNA during stay } \\
\text { Discharge POD } 5 \\
\text { LOS } 120 \text { hr } \\
\text { MIS TLIF, } 1 \text { level }\end{array}$ & $\begin{array}{l}\text { Inpatient } \\
\text { POD } 1 \text { - Fever } 1\left(38.6^{\circ} \mathrm{C}\right)^{\dagger}, 39 \mathrm{hr} \\
\text { POD } 1 \text { - UA/UCx - Normal } \\
\text { POD } 1 \text { - CXR, CT - Atelectasis } \\
\text { POD } 1 \text { - WBC max (13.1), CRP (63.2) } \\
\text { POD } 2 \text { - BCX - Normal } \\
\text { POD } 2 \text { - CT - PNA* }\end{array}$ & $\begin{array}{l}\text { POD } 0 \text { - Tachycardia overnight } \\
\text { POD } 1 \text { - Continued tachycardia. Complained of sore throat. } \\
\text { Oxygen saturation percent dropped to high 80s overnight } \\
\text { POD } 2 \text { - Second CT demonstrated bibasilar opacities, treated for } \\
\text { PNA. Did not complain of chest pain or shortness of breath. }\end{array}$ \\
\hline $\begin{array}{l}\text { Patient E } \\
53 \text { Male } \\
\text { DVT after discharge } \\
\text { Discharge POD } 4 \\
\text { LOS } 103 \mathrm{hr} \\
\text { MIS TLIF, } 1 \text { level }\end{array}$ & $\begin{array}{l}\text { Inpatient } \\
\text { POD } 0 \text { - Fever } 1\left(38.9^{\circ} \mathrm{C}\right), 13 \mathrm{hr} \\
\text { POD } 1 \text { - Fever } 3\left(39.2^{\circ} \mathrm{C}\right)^{\dagger}, 18 \mathrm{hr} \\
\text { POD } 1 \text { - WBC } \max (18.3) \\
\text { Outpatient } \\
\text { POD } 18 \text { - Duplex - DVT }\end{array}$ & $\begin{array}{l}\text { POD } 1 \text { - Had urinary retention and received straight catheteriza- } \\
\text { tion. Fevers resolved after POD } 1 . \\
\text { POD } 4 \text { - Discharged. No DVT symptoms during stay. } \\
\text { POD } 18 \text { - Developed pain and swelling in calf. Outside ER diag- } \\
\text { nosed DVT with Duplex ultrasound. Started on anticoagulation. }\end{array}$ \\
\hline $\begin{array}{l}\text { Patient F } \\
72 \text { Female } \\
\text { DVT, UTI after discharge } \\
\text { Discharge POD } 6 \\
\text { LOS } 142 \mathrm{hr} \\
\text { PLF, } 1 \text { level }\end{array}$ & $\begin{array}{l}\text { Inpatient } \\
\text { POD } 1 \text { - Fever } 1\left(38.9^{\circ} \mathrm{C}\right)^{\dagger}, 16 \mathrm{hr} \\
\text { POD } 2 \text { - WBC } \max (15.0) \\
\text { POD } 4 \text { - UA/UCx - Normal } \\
\text { Rehabilitation facility } \\
\text { POD } 7 \text { - UA/UCx - UTI }{ }^{\star} \\
\text { POD } 19 \text { - Duplex - DVT } \\
\text { Outpatient } \\
\text { POD } 34 \text { - Duplex - DVT* }\end{array}$ & $\begin{array}{l}\text { POD } 1 \text { - Had urinary retention, frequency. Received straight } \\
\text { catheterization. } \\
\text { POD } 6 \text { - Transfer to rehabilitation facility for further physical } \\
\text { therapy, pain management. } \\
\text { POD } 7 \text { - Continued urinary frequency. UA demonstrated bacte- } \\
\text { ria, leukesterase. Started on antibiotics. } \\
\text { POD } 19 \text { - Developed leg edema without tenderness. Duplex } \\
\text { ultrasound demonstrated right calf DVT. } \\
\text { POD } 34 \text { - Presented to ER with leg pain, swelling. Duplex ultra- } \\
\text { sound demonstrated left calf DVT. Started on anticoagulation. }\end{array}$ \\
\hline $\begin{array}{l}\text { Patient G } \\
63 \text { Male } \\
\text { UTI after discharge } \\
\text { Discharge POD } 3 \\
\text { LOS } 79 \text { hr } \\
\text { ALIF, } 1 \text { level }\end{array}$ & $\begin{array}{l}\text { Inpatient } \\
\text { POD } 1 \text { - Fever } 1\left(38.6^{\circ} \mathrm{C}\right)^{\dagger}, 35 \mathrm{hr} \\
\text { POD } 2 \text { - UA/UCx - Normal } \\
\text { Outpatient } \\
\text { POD } 24 \text { - UA/UCx - UTI* }\end{array}$ & $\begin{array}{l}\text { POD } 2 \text { - Developed abdominal distention and urinary retention. } \\
\text { POD } 24 \text { - Called office reporting urinary symptoms. Went to } \\
\text { outside ER and diagnosed UTI based on UA. } \\
\text { No WBC elevation during stay }\end{array}$ \\
\hline
\end{tabular}

POD, postoperative day; LOS, length of stay; POD, postoperative day; MIS TLIF, minimally invasive transforaminal lumbar interbody fusion; PLF, posterior lumbar fusion; ALIF, anterior lumbar interbody fusion; UA, urinalysis; UCx, urine culture; CXR, chest X-ray; CT, computed tomography; BCX, blood culture; PNA, pneumonia; UTI, urinary tract infection; DVT, deep vein thrombosis; ER, emergency room; CSF, cerebrospinal fluid; WBC, white blood count $(\mathrm{K} / \mu \mathrm{L})$; CRP, C-reactive protein $(\mathrm{mg} / \mathrm{L})$.

${ }^{\star}$ Signifies final diagnosis. ${ }^{\dagger}$ Indicates peak fever. 
In a cohort of pediatric patients undergoing posterior spinal fusion predominantly for scoliosis correction, Blumstein et al. ${ }^{22}$ reported fever rates of $72 \%$ and $9 \%$ when using temperature cutoffs of $38^{\circ} \mathrm{C}$ and $39^{\circ} \mathrm{C}$, respectively. The difference in fever rates between Blumstein's reported values and the results of this study are likely multifactorial. First, deformity correction surgery is longer and requires more tissue destruction than the surgeries performed in the present study. The release of inflammatory cytokines such as interleukin- 6 that occurs with tissue damage has been demonstrated to directly correlate with the development of fevers. As such, it is intuitive that a more invasive procedure with increased tissue damage would result in an increased release of cytokines and thus a greater likelihood of postoperative pyrexia. ${ }^{27-29}$ Second, pediatric patients experience postoperative fevers more frequently than adults following orthopedic surgery. ${ }^{1}$ Lastly, the different temperature thresholds used by Blumstein make it difficult to properly compare the fever incidences.

Many patients with undetermined etiologies on diagnostic fever workup were presumed to have atelectasis or other selflimited pathologies. As a result, only $8.5 \%$ of patients who underwent a fever workup had a result indicative of a complication during the inpatient period. Prior studies have reported that fevers occurring after POD 3, lasting longer than 24 hours, reaching a maximum greater than $39^{\circ} \mathrm{C}$, or being associated with the presence of a second temperature spike all may be more indicative of an infectious complication..$^{11,21,30,31}$ The patients in the present study who developed complications during their inpatient stay either presented with symptoms associated with their eventual diagnosis, had fevers greater than $39^{\circ} \mathrm{C}$ or other abnormal vital signs, or experienced a second episode of fever. These results suggest that fever workups may not be efficacious in the absence of other signs or symptoms. As the majority of fever work-ups are inconclusive, clinical signs of potential complications should be used as a guide to assist in diagnosis without excessive testing.

The patients who developed complications after discharge were unlikely to be captured by the inpatient workup due to their delayed presentation. Patient E developed a DVT 14 days after discharge, while patient G developed a UTI 21 days after discharge. In both instances their inpatient fevers were likely not related to these complications. Conversely, Patient F was diagnosed with a UTI 1 day after discharge to a rehabilitation facility, despite having negative UA and urine culture prior to discharge. However, this patient was experiencing symptoms consistent with a UTI throughout their stay and was suspected to have an infection, but was not started on or discharged with antibiotic therapy. Of note, the only fever this patient experienced was on POD 1, 16 hours following surgery. This patient also experienced two separate DVTs in different legs on POD 19 and POD 34, significantly after her discharge. The first DVT was not treated with any anticoagulation at that time. Following the second DVT, the patient was put on a long-term anticoagulation regimen. In each of these patients, the complications experienced after discharge were likely unrelated to the fevers they experienced during hospitalization due to the prolonged time between the fever and the diagnosis, emphasizing the limited utility of a fever episode in guiding a diagnostic workup. Importantly, each patient recognized his or her symptoms as an outpatient and sought medical care.

The only risk factors for the development of fever were operations longer than 150 minutes and a total narcotic consumption on POD 0 greater than 85 OMEs (mg). Longer operations have previously been reported as a risk factor for postoperative fever, infection, and other complications following orthopedic surgeries. ${ }^{32-38}$ As previously described, the increased length of procedures has been theorized to result in a greater amount of tissue damage and subsequent pyrogen release. Thus, increased procedure time would be a significant risk factor for the development of postoperative fever. In a similar light, the surgical wound is exposed for a greater length of time, increasing the risk of contamination during the operative procedure.

The increased risk of fever with greater narcotic dosage has also been reported in the literature. In a retrospective review of 3,613 patients undergoing total joint arthroplasty, Karam et al. ${ }^{14}$ reported that patients who received a multimodal analgesia protocol developed fewer fevers when compared to a cohort who received a narcotic based, patient controlled analgesia (PCA) protocol. This phenomenon is likely due to the anti-pyretic qualities of many of the nonnarcotic analgesics used in a multimodal analgesia protocol. While narcotics have been reported to promote fever, an immunosuppressive effect has also been noted. Beilin et al. ${ }^{39}$ reported that fentanyl suppresses natural killer cell cytotoxicity and therefore may weaken immune response. However, the clinical relevance of immunomodulator effects of narcotics remains unclear. ${ }^{40}$ As such, narcotic medications should not be limited in an attempt to control pyrexia at the expense of adequate pain control. Rather narcotic dose should be considered as a potential contributor to elevated temperatures when debating whether to pursue a fever workup.

The present study is not without limitations. First, this was a retrospective review of a single surgeon's operative experience, 
limiting generalizability. Second, due to the retrospective nature of this study, patient management protocols could not be controlled. Not every patient who developed a fever was worked up for a possible cause and the determination of work-up components was based upon clinical judgement of the treatment team. However, this study provides preliminary data regarding the development of inpatient fever following lumbar fusion procedures that can be utilized to help direct future investigations. Third, more recent patients received a multimodal analgesia protocol, while earlier patients received a PCA pain management strategy, potentially reducing the number of fevers observed in the later patients. While previous studies have suggested that the increased utilization of medications with antipyretic properties in multimodal analgesia protocols can limit fever developement, this has not translated to differences in the identification of complications. ${ }^{14}$ Fourth, it is possible that some first fever episodes may have occurred after discharge and therefore were not included in this analysis. However, the primary focus of this study was to describe postoperative fevers as identified on routine inpatient monitoring in order to help guide decision making in this setting. Lastly, a relatively small number of patients developed postoperative fevers, with even fewer developing a complication. This limited the statistical ability to stratify patients with fever by the presence of a complication, analyze risk factors for complications, or determine the elements of a fever workup with the greatest utility in identifying a cause.

\section{CONCLUSION}

In summary, approximately 1 in 8 patients develop at least one inpatient fever following lumbar fusion surgery. In a majority of these cases, no cause for fever is detected. However, patients who do have a complication-associated fever will likely present with signs or symptoms consistent with their complication. As such, fever workups following lumbar fusion may be unnecessary unless pursued with the guidance of a postoperative symptom suggesting a potential source. Patients who underwent longer operations and those who consumed a greater amount of narcotic medications on POD 0 were at greater risk of developing postoperative fever. These factors may be considered when defining the risks and benefits of performing a diagnostic workup. Despite the relative rarity of complications following lumbar fusions, it is critical that patients are adequately educated on possible symptoms that may indicate an adverse event and to seek medical care when necessary.

\section{CONFLICT OF INTEREST}

The authors have nothing to disclose.

\section{ACKNOWLEDGMENTS}

Preliminary portions of this work have been presented at Society for Minimally Invasive Spine Surgery 2016, Lumbar Spine Research Society 2017, North American Spine Society 2017, International Society for the Advancement of Spine Surgery 2018, and American Academy of Orthopaedic Surgeons 2018.

\section{REFERENCES}

1. Angel JD, Blasier RD, Allison R. Postoperative fever in pediatric orthopaedic patients. J Pediatr Orthop 1994;14:799-801.

2. Athanassious C, Samad A, Avery A, et al. Evaluation of fever in the immediate postoperative period in patients who underwent total joint arthroplasty. J Arthroplasty 2011;26:1404-8.

3. Uçkay I, Agostinho A, Stern R, et al. Occurrence of fever in the first postoperative week does not help to diagnose infection in clean orthopaedic surgery. Int Orthop 2011;35:125760 .

4. Czaplicki AP, Borger JE, Politi JR, et al. Evaluation of postoperative fever and leukocytosis in patients after total hip and knee arthroplasty. J Arthroplasty 2011;26:1387-9.

5. Lesperance R, Lehman R, Lesperance K, et al. Early postoperative fever and the "routine" fever work-up: results of a prospective study. J Surg Res 2011;171:245-50.

6. Guinn S, Castro FP Jr, Garcia R, et al. Fever following total knee arthroplasty. Am J Knee Surg 1999;12:161-4.

7. Kenan S, Liebergall M, Simchen E, et al. Fever following orthopedic operations in children. J Pediatr Orthop 1986;6:139 42.

8. Kennedy JG, Rodgers WB, Zurakowski D, et al. Pyrexia after total knee replacement. A cause for concern? Am J Orthop (Belle Mead NJ) 1997;26:549-52, 554.

9. Shaw JA, Chung R. Febrile response after knee and hip arthroplasty. Clin Orthop Relat Res 1999;(367):181-9.

10. Ballestas HC. Postoperative fever: to what is the body really responding? AORN J 2007;86:983-8.

11. Andres BM, Taub DD, Gurkan I, et al. Postoperative fever after total knee arthroplasty: the role of cytokines. Clin Orthop Relat Res 2003;415:221-31.

12. Ward DT, Hansen EN, Takemoto SK, et al. Cost and effectiveness of postoperative fever diagnostic evaluation in total 
joint arthroplasty patients. J Arthroplasty 2010;25(6 Suppl): 43-8.

13. Fanning J, Brewer J. Delay of hospital discharge secondary to postoperative fever--is it necessary? J Am Osteopath Assoc 2002;102:660-1.

14. Karam JA, Zmistowski B, Restrepo C, et al. Fewer postoperative fevers: an unexpected benefit of multimodal pain management? Clin Orthop Relat Res 2014;472:1489-95.

15. Badillo AT, Sarani B, Evans SR. Optimizing the use of blood cultures in the febrile postoperative patient. J Am Coll Surg 2002;194:477-87.

16. de la Torre SH, Mandel L, Goff BA. Evaluation of postoperative fever: usefulness and cost-effectiveness of routine workup. Am J Obstet Gynecol 2003;188:1642-7.

17. Schey D, Salom EM, Papadia A, et al. Extensive fever workup produces low yield in determining infectious etiology. Am J Obstet Gynecol 2005;192:1729-34.

18. Fanning J, Neuhoff RA, Brewer JE, et al. Frequency and yield of postoperative fever evaluation. Infect Dis Obstet Gynecol 1998;6:252-5.

19. Anderson JT, Osland JD. Blood cultures for evaluation of fever after total joint arthroplasty. Am J Orthop (Belle Mead NJ) 2009;38:E134-6.

20. Bindelglass DF, Pellegrino J. The role of blood cultures in the acute evaluation of postoperative fever in arthroplasty patients. J Arthroplasty 2007;22:701-2.

21. Tai TW, Chang CW, Lin CJ, et al. Elevated temperature trends after total knee arthroplasty. Orthopedics 2009;32:886.

22. Blumstein GW, Andras LM, Seehausen DA, et al. Fever is common postoperatively following posterior spinal fusion: infection is an uncommon cause. J Pediatr 2015;166:751-5.

23. Seo J, Park JH, Song EH, et al. Postoperative nonpathologic fever after spinal surgery: incidence and risk factor analysis. World Neurosurg 2017;103:78-83.

24. Walid MS, Sahiner G, Robinson C, et al. Postoperative fever discharge guidelines increase hospital charges associated with spine surgery. Neurosurgery 2011;68:945-9.

25. Charlson ME, Pompei P, Ales KL, et al. A new method of classifying prognostic comorbidity in longitudinal studies: development and validation. J Chronic Dis 1987;40:373-83.

26. Narayan M, Medinilla SP. Fever in the postoperative patient. Emerg Med Clin North Am 2013;31:1045-58.

27. Frank SM, Kluger MJ, Kunkel SL. Elevated thermostatic setpoint in postoperative patients. Anesthesiology 2000;93:142631.
28. Miyawaki T, Maeda S, Koyama Y, et al. Elevation of plasma interleukin-6 level is involved in postoperative fever following major oral and maxillofacial surgery. Oral Surg Oral Med Oral Pathol Oral Radiol Endod 1998;85:146-52.

29. Buvanendran A, Kroin JS, Tuman KJ, et al. Effects of perioperative administration of a selective cyclooxygenase 2 inhibitor on pain management and recovery of function after knee replacement: a randomized controlled trial. JAMA 2003; 290:2411-8.

30. Lu X, Jin J, Lin J, et al. Course of fever and potential infection after total joint replacement. Knee Surg Sports Traumatol Arthrosc 2015;23:1870-6.

31. Engoren M. Lack of association between atelectasis and fever. Chest 1995;107:81-4.

32. Basques BA, Fu MC, Buerba RA, et al. Using the ACS-NSQIP to identify factors affecting hospital length of stay after elective posterior lumbar fusion. Spine (Phila Pa 1976) 2014; 39:497-502.

33. Carreon LY, Puno RM, Dimar JR 2nd, et al. Perioperative complications of posterior lumbar decompression and arthrodesis in older adults. J Bone Joint Surg Am 2003;85-A: 2089-92.

34. Maoz G, Phillips M, Bosco J, et al. The Otto Aufranc Award: modifiable versus nonmodifiable risk factors for infection after hip arthroplasty. Clin Orthop Relat Res 2015;473:453-9.

35. Nakanishi T, Araki H, Ozawa N, et al. Risk factors for pyrexia after endoscopic submucosal dissection of gastric lesions. Endosc Int Open 2014;2:E141-7.

36. Shi C, Yang C, Gao R, et al. Risk factors for delirium after spinal surgery: a meta-analysis. World Neurosurg 2015;84: 1466-72.

37. Siemionow K, Pelton MA, Hoskins JA, et al. Predictive factors of hospital stay in patients undergoing minimally invasive transforaminal lumbar interbody fusion and instrumentation. Spine (Phila Pa 1976) 2012;37:2046-54.

38. Willis-Owen CA, Konyves A, Martin DK. Factors affecting the incidence of infection in hip and knee replacement: an analysis of 5,277 cases. J Bone Joint Surg Br 2010;92:1128-33.

39. Beilin B, Shavit Y, Hart J, et al. Effects of anesthesia based on large versus small doses of fentanyl on natural killer cell cytotoxicity in the perioperative period. Anesth Analg 1996; 82:492-7.

40. Negishi C, Lenhardt R. Fever during anaesthesia. Best Pract Res Clin Anaesthesiol 2003;17:499-517. 